\title{
ЧЕЛОВЕЧЕСКИЕ ЭКЗИСТЕНЦИАЛЫ
}

\author{
Л.В. Чеснокова
}

\section{ЭКЗИСТЕНЦИАЛЬНЫЙ СТРАХ И ВЛЕЧЕНИЕ К БЕЗДНЕ: КОНЦЕПТЫ ГЛУБИНЫ (Tiefe) И ПРОПАСТИ (Abgrund) В НЕМЕЦКОЙ КУЛЬТУРЕ}

Аннотация. Предметом исследования послужили два важнейших немецких концепта: глубина (Тіеfе) и пропасть / бездна (Abgrund). Они нашли свою глубокую проработку во многих областях немецкой культуры, в языке и философии. Эти концепты амбивалентны: с одной стороны, пропасть внушает человеку страх, а с другой - притягивает его к себе. В немецкой культуре традиционно присутствует стремление к глубине как в переносном смысле: к глубине творческих исканий, так и в прямом: к глубинам земли. Это тяготение в глубину, нашедшее своё отражение в мифологии и религии, литературе и искусстве, науке и промышленности связано с вертикальной моделью немецкой культуры, отразившейся в высотах и падениях духа. Теоретико-методологической основой статьи был выбран культурфилософский подход, согласно которому национальная культура является областью формирования и функционирования концептов. В исследовании используется метод концептуального анализа (методика Ю.С. Степанова), позволяющая выявить культурозначимые характеристики описываемых концептов. Научная новизна исследования заключается в том, что в статье был осуществлен культурфилософский анализ концептов глубины (Тіеfе) и пропасти/бездны (Abgrund) и выявлено их значение для немецкой культуры. Были отмечены основные фракторы, влияющие на формирование данных культурных концептов и показана их укорененность в немецкой культуре.

Ключевые слова: культурология, концепт культуры, немецкая культура, национальный менталитет, глубина (Tiefe), пропасть/бездна (Abgrund), экзистенциальный страх (Angst), подземный мир, готика, фаустианство.

Review. The subject of the research is the two most important German concepts, the concept of the depth (Tiefe) and the concept of the abyss (Abgrund). These concepts have had the in-depth analysis in most spheres of German culture, language and philosophy. These are ambivalent concepts. On the one hand, the abyss arouses fear in a man, on the other hand, it beckons him. German culture traditionally presents the drive to the abyss both figuratively, i.e. to the depth of creative searches, and literally, to the depth of earth. This drive to the depth that has been reflected in mythology and religion, literature and art, science and industry, is associated with the vertical model of German culture, ups and downs of spirit. The theoretical and methodological basis of the article involves the cultural-philosophical approach which views national culture as the sphere of formation and functioning of concepts. The researcher has used the method of the conceptual analysis (as it was offered by Yu. Stepanov) allowing to define the culturally important features of the described concepts. The scientific novelty of the research is caused by the fact that the researcher has conducted the cultural-philosophical concepts of Tiefe and Abgrund and defined their role for German culture. The researcher has also described the main factors influencing the development of these cultural concepts and demonstrated their crucial role for German culture.

Keywords: underworld, Angst (existential fear), Abgrund (abyss), cultural studies, concept of culture, German culture, national mentality, Tiefe (depth), Gothic art, Faustianism.

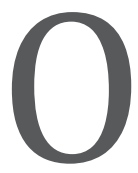

дним из основных терминов современных гуманитарных наук является концепт, который Ю.С.Степанов определяет как микромодель культуры, порождающий её и порождаемый ею. «Концепт - это как бы сгусток культуры в сознании человека; то, в виде чего культура входит в ментальный мир человека. И, с другой стороны, концепт - это то, посредством чего человек - обычный, рядовой человек, не “творец культурных ценностей" - сам входит в культуру, а 
в некоторых случаях и влияет на неё» ${ }^{1}$. У каждого народа имеются ключевые слова, в осмыслении и интерпретации которых раскрываются его особенности мышления и менталитет. Обозначая главные понятия духовной культуры, они сами являются ее элементами и получают в ней свое осмысление.

Предметом настоящего исследования являются концепты глубины (Tiefe) и пропасти (Abgrund) в немецкой культуре. Традиционно в качестве одной из наиболее примечательных черт немецкого мышления называется стремление к истине, содержательности и глубине, пусть даже сочетающихся с известной тяжеловесностью изложения и сложностью для восприятия. Вспомним ироничную пушкинскую формулировку, характеризующую немецкую культуру, к которой приобщился Ленский в одном из германских университетов: «и нечто, и туманну даль».

Германию называют «страной мыслителей и поэтов» (Dichter und Denker). Глубокое содержание здесь считается гораздо более важным, чем форма изложения. Поэтому Гегель в ответ на запрос из Франции изложить им кратко и популярно свою систему, сообщил, что его система не может быть изложена ни кратко, ни популярно, ни пофранцузски.

В этом смысле существует разительное отличие между французской и немецкой культурами. Французская мысль славится своей рациональной ясностью. Восточнее же ее границ находится германский мир, который для многих французов несет в себе черты завораживающей глубины и иррациональности. Немецкий Geist (дух) является противоположностью французскому esprit. Как отмечает Х.-Д. Гельферт, «esprit ясен, подвижен, прозрачен и имеет своим идеалом Прекрасное; немецкий же дух темен, глубок, преисполнен мечтательной медлительности и его эстетическим идеалом является Возвышенное»².

В отличие от Geist, тяготеющего к духовной глубине, esprit стремится избежать слишком большой серьезности и сложности, в которых он видит педантизм, отдающий дурным тоном. Во французской интеллектуальной среде не строятся сложные многосоставные конструкции немецких философских систем, а спор ведётся легко, как бы играючи,

\footnotetext{
1 Степанов Ю.С. Константы: словарь русской культуры. М.: Академический проект, 2004. С. 43.

2 Gelfert H.-D. Typisch englisch Wie die Briten wurden, was sie sind. München: Beck, 2005. S. 118.
}

в нём ценятся меткие, искрометные остроумные bonmots, а не тяжеловесные формулировки.

До середины XX в. многие немецкие интеллектуалы чувствовали себя вовлеченными в это немецко-французское противостояние «культуры» и «цивилизации». Немцы, почти так же как и русские, чувствовали себя отделенными непреодолимой пропастью от западного мира. Типичным примером тому может послужить один из самых известных немецких писателей Томас Манн, считавший французскую культуру слишком поверхностной. Немецкий же дух (Geist) представляется ему «более глубоким культурным явлением, находящимся между двумя полюсами напряжения: темным иррационализмом русской души и плоским рационализмом западного Просвещения и объединяющим в себе рациональность и душевность, глубину и ясность» ${ }^{3}$.

Немецкие мыслители и поэты традиционно предпочитают глубокие, серьезные темы, а немецкой литературе в целом свойственна определенная тяжеловесность и пессимизм. Можно предположить, что подобная любовь к глубине - не простое предпочтение, а выражение определенного мировоззрения, присущего немецкой культуре, выбравшей путь к высотам и падениям духа. Поэтому немецкой амплитуде культуры присуща вертикальная устремленность: высочайшие творения духа и глубочайшие падения, шпили готических соборов, рвущиеся в небо, и глубина философских исканий.

Г.Д. Гачев объясняет вертикальный вектор германства следующим образом: «Стремление, восстание, превосхождение мер - это действие стихии огня, которая побуждает душу восходить ввысь, в Нӧһе. Инерция же, статика - производятся гравитацией земли, которая притягивает континентальную германскую душу с равной силой в глубь (Tiefe). Немец распялен между этими двумя полюсами вертикали Бытия» ${ }^{4}$.

Если романские народы их savoire vivre (искусством жить) спокойно и одобрительно относятся к существующему земному миру и телесности, а русским есть где разгуляться на своих бескрайних просторах, то немец, чувствуя себя зажатым в центре Европы, стремится вырваться за данные ему пределы, что возможно только по вертикали: вверх или вниз.

Gelfert H.-D. Typisch englisch .Wie die Briten wurden, was sie sind. München: Beck, 2005. S. 118.

4 Гачев Г.Д. Ментальности народов мира. М.: Эксмо, 2008. C. 116. 


\section{Философия и культура 7(91) • 2015}

И наоборот, основной вектор русской культуры - это горизонталь. В отличие от европейского обостренного чувства формы, жесткой структурированности, здесь присутствует бесформенность, горизонтально растянутая картина мира, равнинное мышление. Величина русского пространства контрастирует с малыми размерами и территориальной разделённостью Западной Европы. По словам Ф. Ингольда, для русского человека «ощущение родных просторов прежде всего связывается с чувством большей свободы, «воли», которая искушает его забыть самого себя, странствовать, оставив все, что связывает его с прошлым и с будущим, с его работой, семьей, домом» ${ }^{5}$. Напротив, в пространственной тесноте Европы взгляд все время натыкается на какие-то границы (реки, горы, моря, озера...); человек здесь не может и шагу ступить, чтобы не столкнуться с каким-то законом - в противоположность «воле», ощущению русского простора.

Наиболее явственно стремление вверх по вертикальной оси немецкой культуры отразилось в готической архитектуре. В организации пространства, согласно О.Шпенглеру, отражается менталитет народа. Фаустовской культуре свойственна любовь к чистому, бесконечному пространству, проявившаяся в двух явлениях духа: готической архитектуре и инструментальной музыке.

Архитектурная форма пространственно отражает представления о мире и человеке, о его связи с трансцендентным началом, неповторимые для каждой культуры. Если, как пишет Е. Трубецкой, «византийский купол над храмом изображает собой свод небесный, покрывающий землю, наша отечественная «луковица» воплощает собой идею глубокого молитвенного горения к небесам, то готический шпиц выражает собой неудержимое стремление ввысь, подъемлющее от земли каменные громады» ${ }^{6}$. Наиболее характерной чертой готической архитектуры является устремленность ввысь. Здесь, точно так же, как и в органной музыке, мы наблюдаем вертикальную устремлённость к небу с обестелесниванием материи, стремление превратить тяжеловесный камень в невесомые воздушные конструкции.

5 Ingold F.P. Russische Wege. Geschichte - Kultur - Weltbild. München: Fink, 2007. S. 88-89.

6 Трубецкой Е. Н. Умозрение в красках // Философия русского религиозного искусства XVI-XX вв. М.: Прогресс, 1993. C. 198.
Хотя готический стиль в архитектуре присутствует в большинстве западноевропейских стран, однако наибольшим своеобразием отличается именно немецкая готика, создавшая свой собственный, необычный тип собора, которому свойственно отсутствие гармонии между горизонтальными и вертикальными пропорциями при явном преобладании вертикальных форм. У 0. Шпенглера именно готический собор - символ фаустовской культуры, в котором отражается «мощный феномен готической души, устремляющейся в великолепном порыве через все границы видимой чувственности» ${ }^{7}$.

Средневековые города соревновались между собой, пытаясь построить самый высокий собор. Большинство готических церквей строились очень подолгу, десятилетия, если не столетия. Так, жители Ульма ждали, когда будет завершено строительство Кельнского собора, чтобы впоследствии превзойти его по высоте (161 метр против 156 метров в Кельне). Как отмечает А. Демандт, эти гигантские сооружения изначально превосходили все практические цели: «ульмский Мюнстер вмещает почти 20 тысяч посетителей, что более чем в два раза превышает количество жителей, проживавших в то время в Ульме» ${ }^{8}$ Стоимость такого строительства могла поглотить весь городской бюджет, при том, что жилища большинства горожан в те времена были скромными деревянными постройками.

Другим, внешне противоположным, но внутренне родственным готической архитектуре, выражением немецкой культуры, является инструментальная музыка, которой традиционно славится Германия. Это феномен, выражающий внутреннюю ментальность культуры. По словам T. Манна, «если Фауст является представителем германской души, то он должен быть музыкальным, так как абстрактно и мистично, то есть музыкально отношение немцев к миру, отношение одержимого дьяволом профессора, неловкое, но, в то же время, определяемое высокомерным стремлением превзойти мир своей глубиной»' ${ }^{9}$. Немцы подарили миру самую глубокую и серьёзную музыку.

\footnotetext{
7 Шпенглер О. Закат Европы. Очерки морфологии мировой истории. Т. 1. М.: Айрис пресс, 2006. С. 274.

8 Demandt A. Über die Deutschen. Eine kleine Kulturgeschichte. Berlin: Ullstein, 2007. S. 235.

9 Mann T. Deutschland und die Deutschen - цит. по: Das Buch der Deutschen: alles, was man kennen muss (hrsg. von Johannes Thiele). Bergisch Gladbach, 2004. S. 606.
} 
И обратным вектором, с такой же страстной силой тянущим немецкую душу в противоположном направлении, является тяга к глубинам земли. Германской культуре свойственно противоречие между этими двумя вертикальными устремлениями: вверх - к вершинам духа, стремящемуся превзойти человеческие пределы и вниз - к приземленной косности, мещанству, тяжелой педантичности, пресловутой любви к порядку, за что часто упрекают немцев.

Таинственные подземелья издавна интересовали немецких исследователей (средневековых алхимиков, позднее - ученых и промышленников), готовых, подобно Фаусту, пожертвовать собственной душой за их постижение. Труд горняков неоднократно описывался в литературе (Э.Т.А. Гофман, А. фон Арним, Новалис), где горный мастер предстает перед читателями как некий посвящённый в тайны природы, знающий секретные пути, ведущие в недра земли, таящие в себе неисчислимые богатства. Этим объясняются многочисленные предания о кладах, сюжеты о том, как в горах обнаруживают золотую жилу или, вспахивая поле, находят горшок с золотыми монетами. Примечательно, что и возлюбленного/возлюбленную по-немецки ласково зовут «mein Schatz», т.е. «моё сокровище», «мой клад». В этом отражается тяга немецкого сознания в таинственные глубины земли.

Как отмечает Г.Д. Гачев, в немецком фольклоре существует множество преданий о кладах: «то земледелец, землю вспахивая, находит, то на жилу в горе нападают. И это мировоззренческий рефлекс германства: вниз, под корень устремляться, куда направляет любомудров и пародирующий германское глубокомыслие русак Козьма Прутков: „Гляди в корень!"» ${ }^{10}$. Сокровища, хранящиеся в глубинах земли, драгоценные металлы, выступают как светила недр: золото - аналог земного солнца, а серебро - луны.

У представителей других народов также есть легенды о том, что под привычной и надежной земной поверхностью таится нечто невыразимое, неподвластное человеческому рассудку. Античное царство мертвых, Гадес, расположен в глубинах земли. Данте в сопровождении Вергилия в первой части «Божественной комедии» спускается во все более глубокие круги ада. «Но ни певец Орфей, ко-

10 Гачев Г.Д. Национальные образы мира. Эллада, Германия, Франция: опыт экзистенциальной культурологии. М.: Логос, 2008. C. $230-231$. торый напрасно пытается вывести из подземного мира на дневной свет свою возлюбленную Эвридику, ни итальянский поэт не описывали эти подземные царства с чувством такой непреодолимой тяги к таинственным глубинам земли. При всей зачарованности сказочным подземным миром, он оставался для них местом, внушающим прежде всего ужас» ${ }^{11}$

Иначе обстоит дело в немецкой культуре, особенно начала XIX в. Одной из наиболее примечательных особенностей немецкого романтизма является то воодушевление, с которым не только немецкие естествоиспытатели, но и мыслители и поэты от Ахима фон Арнима до Э.Т.А. Гофмана открыли для себя мир подземных рудников и шахт как некую загадочную сферу души.

То обстоятельство, что Германия в XIX в. была ведущей нацией в области горнорудной промышленности и науке не объясняет тот чрезмерный интерес, с которым немецкий дух стремится под землю. Некоторые исследователи пытаются объяснить этот феномен глубоким разочарованием в окружающей действительности. «Чем более немецкая душа разочаровывается и отвращается от посюстороннего бытия, не надеясь на утешение в царстве небесном, тем сильнее ее тянет в подземный мир. Тот, кому поверхность земли кажется холодной и негостеприимной, а небо - слишком туманной утопией, ищет утешение в лоне земли. Неотчуждаемая, истинная родина перемещается в глубину (Tiefe)» ${ }^{12}$. Целью немецких романтиков является всегда напрасная, но, тем не менее, неустанно предпринимаемая попытка так отобразить убогую действительность, чтобы и в ней можно было ощутить бесконечное.

Самый знаменитый из этих исследователей земных глубин - И.В.фон Гёте, который более тридцати лет занимался горнорудной промышленностью в Тюрингии. Ранимый, болезненный, тонко чувствующий Новалис (Фридрих фон Харденберг), умерший от туберкулеза в возрасте 28 лет, не только воспевает труд горняков в своем произведении «Генрих фон Офтердинген», но и сам изучает горное дело во Фрайберге, намереваясь унаследовать место своего отца - управляющего соляными копями. Талантливый ученый-естествоиспытатель и

11 Dorn T., Wagner R. Die deutsche Seele. München: Knaus, 2011. S. 16-17.

12 Dorn T., Wagner R. Die deutsche Seele. München: Knaus, 2011. S. 16. 


\section{Философия и культура 7(91) • 2015}

путешественник Александр фон Гумбольдт делает в конце XVIII в. в Пруссии карьеру как эффективный специалист в горнорудной промышленности. Те же представители немецкой духовной элиты, кто в профессиональном смысле не был связан с горнорудной промышленностью, пытались восполнить этот недостаток с помощью «образовательных путешествий», спускаясь с чувством набожного благоговения в неведомый подземный мир с рудничной лампой в руке.

«Внутрь ведет таинственный путь», - пишет Новалис. В своем романе «Генрих фон Офтердинген», он воспевает горное дело, ибо оно, по его мнению, помогает приблизиться к разгадке человеческого духа. «Горное дело, - говорит Генриху старый мастер, - благословил Господь, не иначе. Какое ремесло, кроме горного дела, так вознаграждает и облагораживает труженика, внушает ему такую веру в мудрое небесное Провидение и сохраняет его сердие в такой младенческой чистоте и невинности. Горняк родился бедняком, и бедняком покидает этот мир. Ему довольно знать, где государство каждого металла и как добыть этот металл; чистого сердцем не прельстит ослепительный блеск сокровищ» ${ }^{13}$.

Металлы теряют свою притягательную силу на поверхности земли, становясь товаром, добывать который приходится нечестными способами. Земные недра раскрывают свои тайны лишь человеку, свободному от нечистых помыслов. Твёрдой почвой может быть подземелье только для того, кто туда спускается без корысти. Тот, кто идет в шахту со стремлением поживиться сокровищами земли - погибает.

Подземные клады охраняют духи земли, издревле обитающие в ее глубинах - гномы. В европейской мифологии они описываются как древние человекоподобные существа, искусные кузнецы и ювелиры, живущие неизмеримо больше людей. Главным их отличием являются большие бороды и маленький рост. Они символизируют скрытые силы, мастерство, тайные знания, храня в недрах земли несметные сокровища - драгоценные камни и металлы, которыми лишь изредка делятся с людьми.

Вертикальное измерение немецкой культуры нашло свое отражение в парадоксальном контрасте между возвышенной, утонченной духовностью

13 Новалис. Генрих фон Офтердинген / Изд. подгот. В.Б. Микушевич. М.: Ладомир: Наука, 2003. С. 41. и определенной тяжестью, неповоротливостью, отсутствием артистической легкости, пресловутым филистерством. Существуют как бы два полюса немецкой культуры: Фауст с его отчаянной жаждой познания, готовый ради него пожертвовать своей душой, заключив пакт с дьяволом, о его противоположность - воплощение бюргерства, мещанства и филистерства, сонный Михель в ночном колпаке.

Из немецкого языка к нам пришло слово «филистер» - человек с узкими взглядами, скучный обыватель. По словам Шопенгауэра, «человек, не имеющий вследствие - нормальной, впрочем, ограниченности своих интеллектуальных сил, никаких духовных потребностей, называется филистером - слово, присущее лишь немецкому языку» ${ }^{14}$. Это выражение происходит от библейского «филистимлянин» (то есть палестинец). В речевой оборот это слово входит в XVIII в., когда на похоронах студента, убитого в стычке с бюргерами, пастор, пользуясь в своей проповеди привычной для протестанта ветхозаветной лексикой, назвал его убийц филистерами. С тех пор это слово стало обозначать скучного обывателя, не имеющего возвышенных интеллектуальных и духовных интересов.

Таким образом, в немецкой культуре парадоксальным образом сочетается стремление в Высь (in die Höhe) и в Глубь (in die Tiefe), и это противотяготение между двумя равно мощными вертикальными ориентациями может, по мнению Г.Д. Гачева дать объяснение «этому противоречию между духом протеста, стремлению к превосхождению мер - и уважением к порядку, мистическим чувством формы, этим тяжелым педантизмом (от лат. pespedis - нога, тоже низ), неподвижностью, трудной строгиваемостью на внешние движения» ${ }^{15}$. Отсюда интимное родство немецкой культуры с глубиной, недрами земли, как и культ глубины духа, мысли в германской философии и музыке.

Несомненно, такой вектор культуры не может не таить в себе серьезную духовную опасность, так как эта вертикаль может вести как вверх, так и вниз, ибо того, кто так любит глубину (Tiefe), должно тянуть и в пропасть (Abgrund). Тяга к пропасти, которая одновременно притягивает к себе и внушает страх, - одна из наиболее примечательных черт немецкой культуры. Как отмечает философ,

14 Шопенгауэр А. Афоризмы житейской мудрости // Шопенгауэр А. Избр. произв. М.: Просвещение, 1993. С. 217.

15 Гачев Г.Д. Ментальности народов мира. М.: Эксмо, 2008. C. 116. 
острее всех чувствовавший ее дыхание, «если долго вглядываться в бездну, бездна начинает вглядываться в тебя». В стихотворении «Меж коршунов» из «Дифирамбов Дионису», одном из последних произведений, написанных Ницше незадолго до того, как он сам погрузился в пучину безумия, хищная птица насмехается над повисшим над пропастью Заратустрой:

\author{
Кто захочет здесь вниз, \\ как мгновенно \\ канет он в бездну! \\ - Но ты, Заратустра, \\ бездны всё ещё любишь, \\ как вон та сосна? - \\ Она-то пустит корни, \\ где содрогнётся от страха \\ даже утёс; \\ она-то медлит над бездной, \\ где всё окрест \\ рвётся вниз: \\ меж нетерпеньем \\ водопадов буйных и камнепадов \\ ждёт она терпеливо, сурово, безмолвно, \\ одиноко... \\ Одиноко! \\ Да и кто решится \\ гостем здесь быть, \\ твоим гостем? \\ Коршун разве - \\ налетит и злорадно \\ вцепится в волосы \\ стойкому терпеливцу - \\ с хохотом диким, \\ с хохотом хищным... \\ «К чему эта стойкость? - \\ глумится жестокий. - \\ Любишь бездны - \\ имей крылья! \\ Что ж ты повис тут, \\ висельник жалкий?» <...>
}

(Пер. А.В. Карельского).

Обостренное ощущение бездны отразилось в немецкой философии. Ф. Ницше наиболее отчётливо выразил это мироощущение, сформулировав, что человеческая культура - «это лишь тонкая яблочная кожура над раскаленным хаосом». Иллюзии в виде религии, морали, гуманизма, демократии - лишь паллиативы, помогающие заглушить первозданный ужас от столкновения с бездной.
Высшие люди - аристократы духа - отвергают эти иллюзии, не боясь взглянуть в лицо хаоса. «Человек - это канат, натянутый между животным и сверхчеловеком, - канат над пропастью. Опасно прохождение, опасно быть в пути, опасен взор, обращенный назад, опасны страх и остановка. В человеке важно то, что он мост, а не цель: в человеке можно любить только то, что он переход и гибель. Я люблю тех, кто не умеет жить иначе, как чтобы погибнуть, ибо идут они по мосту» ${ }^{16}$.

Другой выдающийся немецкий философ, М. Хайдеггер, также исследует пропасти бытия и мышления. Пропасть Ничто может поглотить рискнувшего слишком близко подойти к ней. Но истинное философское вопрошание заглядывает в пропасть, отказывается от привычной обыденности, усыпляющей человека, дарящей иллюзию безопасности. Хайдеггер осуждает философию, которая ищет последние основания, надеясь тем самым «закрепить крюки альпинистской страховки (такие как идеи добра, истины и красоты) над пропастью. Философ должен выдерживать головокружения, которые охватывают его, когда он узнает, что в мире не существует никакого надежного основания» ${ }^{17}$.

Он обращается к сидящему глубоко внутри страху, который человек прячет за своей повседневной рутиной: ужас перед тем, что кажущийся стабильным мир, включая его собственную экзистенцию, может рухнуть в любой момент. Человек не способен найти ответ на вопрос, почему почва уходит у него из-под ног, так как на него нет ответа. Поэтому следует учиться жить с чувством беспочвенности перед лицом бездны. Хайдеггер считает, что философ не должен более пытаться бежать от страха перед пропастью Ничто, а исследовать глубины бытия и сознания.

Вероятно, подобная тяга к глубине и пропасти связана с тем, что представители немецкой культуры обостренно чувствуют то, насколько тонок слой почвы под ногами, готовой в любой момент разверзнуться и сбросить нас в пропасть, в которой бушуют силы хаоса.

Если пространственной моделью России является горизонталь, бескрайний простор, то немецкой амплитуде культуры присуща вертикальная устремленность: высочайшие творения духа

16 Ницше Ф. Так говорил Заратустра. Книга для всех и не для кого. М.: ЗАО «ОЛМА Медиа Групп», 2002. С. 10.

17 Dorn T., Wagner R. Die deutsche Seele. München: Knaus, 2011. S. 14. 


\section{Философия и культура 7(91) • 2015}

и глубочайшие падения, шпили готических соборов, рвущиеся в небо и глубина философских исканий, и наполненный несметными сокровищами подземный мир. Но тот, кого так влечёт в глубину, рискует упасть в пропасть - недаром в немецкой культуре издавна существуют истории о духовных искушениях человека, заключившего договор со злом, наиболее известной из которых является история доктора Фауста в переложении Гете. В трагических событиях немецкой истории XX в. многие исследователи видят фаустовский сюжет, когда немецкий народ заключил договор со своим искусителем - Гитлером. По словам А.В. Гулыги, «путями Фауста шла вся немецкая культура, «то наклоняясь к пропастям и безднам, то благополучно минуя их, ведомая поиском истины» ${ }^{18}$.
Таким образом, Tiefe (глубина) и Abgrund (пропасть, бездна) являются важнейшими концептами немецкой философии культуры. Они нашли свою глубокую проработку во многих областях немецкой культуры, в языке и философии, особенно в философии экзистенциализма. Эти концепты амбивалентны: с одной стороны, пропасть внушает страх, а с другой - притягивает к себе. В немецкой культуре традиционно присутствует стремление к глубине - как в переносном смысле - к глубине творческих исканий, так и в прямом - к глубинам земли, проявляющееся в мифологии и религии, литературе и искусстве, науке и промышленности. Это связано с вертикальной моделью немецкой культуры, отразившейся в высотах и падениях духа.

\section{Список литературы:}

1. Гачев Г.Д. Ментальности народов мира. М.: Эксмо, 2008.

2. Гачев Г.Д. Национальные образы мира. Эллада, Германия, Франция: опыт экзистенциальной культурологии. М.: Логос, 2008.

3. Гачев Г.Д. Образы Индии (Опыт экзистенциальной культурологии). М.: Наука, 1993.

4. Гулыга А.В. Путями Фауста: этюды германиста. М.: Советский писатель, 1987.

5. Ницше Ф. Так говорил Заратустра. Книга для всех и не для кого. М.: ЗАО «ОЛМА Медиа Групп», 2002.

6. Новалис. Генрих фон Офтердинген / Изд. подгот. В.Б. Микушевич. М.: Ладомир: Наука, 2003.

7. Степанов Ю.С. Константы: словарь русской культуры. М.: Академический проект, 2004.

8. Трубецкой Е.Н. Умозрение в красках // Философия русского религиозного искусства XVI-XX вв. М.: Прогресс, 1993.

9. Шопенгауэр А. Афоризмы житейской мудрости // Шопенгауэр А. Избранные произведения. М.: Просвещение, 1993.

10. Шпенглер О. Закат Европы. Очерки морфологии мировой истории. Т. 1. М.: Айрис пресс, 2006.

11. Demandt A. Über die Deutschen. Eine kleine Kulturgeschichte. Berlin: Ullstein, 2007.

12. Dorn T., Wagner R. Die deutsche Seele. München: Knaus, 2011.

13. Gelfert H.-D. Typisch englisch. Wie die Briten wurden, was sie sind. München: Beck, 2005.

14. Ingold F.P. Russische Wege. Geschichte - Kultur - Weltbild. München: Fink, 2007.

15. Mann T. Deutschland und die Deutschen. (Цит. по: Das Buch der Deutschen: alles, was man kennen muss (hrsg. von Johannes Thiele). Bergisch Gladbach, 2004.)

\section{References (transliteration):}

1. Gachev G.D. Mental'nosti narodov mira. M.: Eksmo, 2008.

2. Gachev G.D. Natsional'nye obrazy mira. Ellada, Germaniya, Frantsiya: opyt ekzistentsial'noi kul'turologii. M.: Logos, 2008.

3. Gachev G.D. Obrazy Indii (Opyt ekzistentsial'noi kul'turologii). M.: Nauka, 1993.

4. Gulyga A.V. Putyami Fausta: etyudy germanista. M.: Sovetskii pisatel', 1987.

5. Nitsshe F. Tak govoril Zaratustra. Kniga dlya vsekh i ne dlya kogo. M.: ZAO «OLMA Media Grupp», 2002.

6. Novalis. Genrikh fon Ofterdingen / Izd. podgot. V.B. Mikushevich. M.: Ladomir: Nauka, 2003.

7. Stepanov Yu.S. Konstanty: slovar' russkoi kul'tury. M.: Akademicheskii proekt, 2004.

8. Trubetskoi E.N. Umozrenie v kraskakh // Filosofiya russkogo religioznogo iskusstva XVI-XX vv. M.: Progress, 1993.

9. Shopengauer A. Aforizmy zhiteiskoi mudrosti // Shopengauer A. Izbrannye proizvedeniya. M.: Prosveshchenie, 1993.

10. Shpengler O. Zakat Evropy. Ocherki morfologii mirovoi istorii. T. 1. M.: Airis press, 2006.

11. Demandt A. Über die Deutschen. Eine kleine Kulturgeschichte. Berlin: Ullstein, 2007.

12. Dorn T., Wagner R. Die deutsche Seele. München: Knaus, 2011.

13. Gelfert H.-D. Typisch englisch. Wie die Briten wurden, was sie sind. München: Beck, 2005.

14. Ingold F.P. Russische Wege. Geschichte - Kultur - Weltbild. München: Fink, 2007.

15. Mann T. Deutschland und die Deutschen. (Tsit. po: Das Buch der Deutschen: alles, was man kennen muss (hrsg. von Johannes Thiele). Bergisch Gladbach, 2004.)

18 Гулыга А.В. Путями Фауста: этюды германиста. М.: Советский писатель, 1987. С. 5. 